\title{
Sol Ana Koroner Arter Hastalı̆̆ı Risk Faktörlerinin Akut Koroner Sendrom ve Stabil Koroner Arter Hastalığı Üzerine Etkisi
}

\author{
The Effect of Risk Factors of Left Main Coronary Artery Disease on Acut Coronary \\ Syndrome and Stable Coronary Artery Disease
}

\author{
Ahmet Öztürk \\ Prof Dr Cemil Taşcıoğlu Şehir Hastanesi Kardiyoloji Kliniği İstanbul, Türkiye \\ Yazışma Adresi / Correspondence: \\ Ahmet Öztürk \\ Prof Dr Cemil Taşcıoğlu Şehir Hastanesi Kardiyoloji Kliniği Şişli, İstanbul, Türkiye \\ T: +905052734389 E-mail : ahmtozturk58@gmail.com \\ Geliş Tarihi / Received : 27.12.2020 Kabul Tarihi / Accepte: 09.04.2021 \\ Orcid : \\ Ahmet Öztürk https://orcid.org/0000-0003-0609-9702 \\ ( Sakarya Tip Dergisi / Sakarya Med J 2021, 11(2):272-278) DOI: 10.31832/smj.847622
}

\footnotetext{
$\ddot{0} z$

Amaç Kardiyovasküler sistem hastalılkları özellikle yașlı nüfusun daha fazla olduğu gelismis ülkeler ve batı dünyası bașta olmak üzere dünvada en önde gelen morbidite ve mortalite sebepleri arasında yerini korumaktadır. Kardiyovasküler hastalıklarına bağlı ölümlerin ise en büyük kısmını koroner arter hastalığı oluşturmaktadır. Mortalitesi ve morbiditesi bu kadar yüksek olan bir hastallkta hastalığı önceden tespit etmek risk faktörlerini belirlemek önem arzetmektedir. Geniş epidemiyolojik çalışmalar sonucunda hastalığa yol açan majör risk faktörleri belirlenmiş olmasına rağmen yeni risk faktörlerini belirlemeye ihtiyaç vardır.

Gereç ve Çalışmada Ocak 2004 ile Nisan 2012 tarihleri arasında akut koroner sendrom (AKS),stabil koroner arter hastalığı kliniği ile hastaneye başvurup yapılan koroner anjiografi Yöntem sonrası izole sol ana koroner arter(LMCA) hastalı̆̆ı tanısı konulan hastaların aterosklerotik risk faktörlerini ve bu risk faktörlerinin klinik gelis tablosu üzerine olan etkisi geriye dönük araștırıldı. Çalışmada koroner arter cerrahisi olanlar,ileri dönem böbrek yetersizliği olanlar,yetersiz klinik ve laboratuvar tetkikleri olanlar LMCA dışında diğer damarlarında ciddi lezyonu olan hastalar çalışmaya alınmadı. İzole sol ana koroner arter hastalı̆̆ı olan hastalar AKS sonrası tanı alanlar grup 1,stabil koroner arter hastalığı sonrası tanı alanlar grup 2 olarak ikiye ayrıldı.

Bulgular Cinsiyet açısından ( $\mathrm{p}=0.02)$, aile öyküsü açısından ( $\mathrm{p}=0.02)$, grup 1 ve grup 2 hastaları arasında istatistiksel olarak anlamlı fark saptandı. Laboratuar tetkiklerinden ise LDL değerleri açısından ( $p=0.03$ ), nötrofil değerleri açısından ( $p=0.005)$, lenfosit değerleri açısından ( $p=0.04)$, monosit değerleri açısından ( $p=0.01)$ hemoglobin değerleri açısından ( $\mathrm{p}=0.005)$, RDW değerleri açısından ( $\mathrm{p}=0.03$ ), nötrofil/lenfosit oranı açısından ( $\mathrm{p}=0.01)$ grup 1 ve grup 2 arasında istatistiksel olarak anlamlı fark saptandı.

Sonuç Sonuç olarak çalıșmamızdan elde edilen veriler benzer çalışmalardaki verileri desteklemekte olup, özellikle neutrofil/lenfosit oranının AKS hastaları lehine yüksek olması gelecekte bu hastaları ön görmede önemli yer tutacağını düşünmekteyiz

Anahtar Akut koroner sendrom; koroner anjiografi; sol ana koroner arter hastalı̆̆l; kardiyovasküler sistem

Kelimeler

Abstract

Objective Cardiovascular diseases remain the leading morbidity and mortality causes in the world especially in developed countries where elderly population is predominant. Coronary artery disease is the leading cause of deaths due to cardiovascular diseases. Early diagnosis is important in determining the risk factors associated with this disease which has such high mortality and morbidity rates. Although major risk factors of the disease have been revealed based on extensive epidemiological studies, additional risk factors need to be found.

Materials In the present study, we studied retrospectively the atherosclerotic risk factors and their effects on clinical prognosis in patients diagnosed with left main coronary artery (LMCA) disease and methods after coronary angiography who presented with acute coronary syndrome (ACS), stable angina pectoris and various other reasons to our hospital in January 2004 and April 2012 period. The patients with coroner artery bypass surgery, advanced renal failure, insufficient clinical and laboratory data and patients with serious lesions in veins other than LMCA were excluded. Patients with LMCA disease were divided into two groups; i.e. the ones whose diagnoses were done after ACS (Group 1) and the ones who had diagnoses after stable angina pectoris (Group 2).

Results There were significant differences for gender $(p=0.02)$ and family history $(p=0.02)$ between Group 1 and Group 2. Regarding laboratory parameters, on the other hand, there were significant differences between Group 1 and Group 2 for LDL levels ( $p=0.03)$, neutrophyl levels ( $p=0.005)$, lenfocite levels $(P=0.04)$, monocyte levels $(p=0.01)$, hemoglobin levels $(P=0.005), R D W$ levels $(p=0.03)$ and neutrophyllenfoctye ratio $(p=0.01)$.

Conclusion In conclusion, the findings of the present study supports the results of the previous similar studies. Particularly, we consider that higher neutrophyl/lenfocyte ratios in ACS patients can be used in future for early diagnosis of the disease.

Keywords Acute coronary syndrome; coronary angiography; left main coronary artery; cardiovascular disease
} 


\section{GIIRIŞ}

Kardiyovasküler sistem hastalıkları (KVS) dünyada önde gelen mortalite ve morbidite nedenidir. KVS hastalıklarına bağlı ölümlerin en büyük kısmını ise koroner arter hastalığı $(\mathrm{KAH})$ oluşturmaktadır. Yapılan çalışmalar sonucu önüne geçilebilecek ve bu kadar yüksek oranda ölüme sebep olan başka bir hastalık tanımlanmamıştır. ${ }^{1} 1990$ yılından itibaren ülkemizde yapılan Türk Erişkinlerinde Kalp Hastalığı ve Risk Faktörleri (TEKHARF) çalışmasının verilerine göre ülkemizde 2 milyonu aşkın KAH hastası olduğu tespit edilmiştir. Bu çalışmada KAH’a bağlı ölüm \%42,5’lik bir oranla tüm nedenler içerisinde en yüksek dilimi oluşturmaktadır. ${ }^{2}$ Gelişmiş ülkelerde yıllık KAH mortalitesinin 45 yaş üstü erkeklerde 0.02-0.09, kadınlarda 0.006-0.03 arasında olduğu, TEKHARF çalışmasına göre ise aynı yaş grubunda KAH'a bağlı mortalite oranı erkeklerde 0.09 , kadınlarda 0.05 olduğu saptanmıştır. ${ }^{2}$

Erişkin nüfusun önemli bir bölümünün bu hastalıktan aktif yaşlarda, yani orta yaş ve erken yaşlılık dönemlerinde etkilenmesi olayın ekonomik boyutunu artırmaktadır. Böylesine önemli bir sağlık sorununda, son derece yüksek maliyetle yürütülebilen tedavi çalışmalarından çok birincil ve ikincil korunma çalışmalarına ağırlık verilmesi gereği açıktır. Birincil korumanın en başta gelen amacı, risk faktörlerinin gelişmesini önlemektir. Özellikle değiştirilebilir risk faktörlerinin izlenmesi ve erken müdahale edilmesi çok büyük önem taşır. Koroner kalp hastalığı tanısı konmuş olan kişilerde ikincil korumanın amacı, koroner damardaki aterosklerotik sürecin ilerlemesini ve bunun üzerine binen trombotik olayları azaltmak böylelikle gerek ölümcül olmayan majör iskemik olayların tekrarını, gerekse kardiyak ölüm oranını düşürmektir. ${ }^{3}$

Ciddi sol ana koroner arter (LMCA) darlı̆̆ı ise KAH 'in daha ciddi boyutudur. Ciddi LMCA darlığı damar lümeninde \%50 veya daha fazla daralmanın olması şeklinde tanımlanmıştır. LMCA hastalığı herhangi bir endikasyon nedeniyle koroner anjiyografi (KAG) uygulanan hastaların \%4-10’unda görülür. ${ }^{4,5}$ Şu ana kadarki bilimsel veriler ışığında LMCA hastalarında mortalite ve morbidite daha yüksektir. Yapılan çalışmalarda izole sol ana koroner lezyonu hastalarında cerrahi revaskülarizasyon ile yaşam süresi 13,3 yıl iken optimal medikal tedavi ile 6,6 yıldır. ${ }^{6}$ Kilavuzlarda (ACC/AHA) izole sol ana koroner lezyonu hastaları için optimal tedavide ilk seçenek cerrahi revaskülarizasyondur. Bu hastalarda klinik durum izole sol ana koroner lezyonu olmayan KAH hastalarına göre daha hızlı kötüleşebilmekte ve tablo kararsız anjina ve miyokard enfarktüsüyle komplike olabilmektedir. ${ }^{6}$ Cerrahi açıdan komorbiditesi yüksek ve yakınması olan sol ana koroner arter lezyonlu hastalarda elektif stent ve akut miyokard infarktüsü sonrası perkütan girişim cerrahiye alternatif olarak değerlendirilebilir. ${ }^{7}$ SYNTAX (SYNergy between percutaneous coronary intervention with TAXus and cardiac surgery) skoru (SS) koroner anatomiyi ve koroner lezyon özelliklerini belirleyen anjiyografik bir skorlama sistemidir. SS tüm koroner arter hastalarında olduğu gibi izole sol ana koroner arter hastalarında da revaskülarizasyon yöntemi ve prognoz hakkında önem arzetmektedir. ${ }^{8}$

Yaptığımız geriye dönük çalışmamızda izole sol ana koroner arter hastalığı risk faktörlerini ve bu risk faktörlerinin hastalığın klinik başvuru tablosu üzerine olan etkilerini araştırmayı amaçladık.

\section{GEREÇ ve YÖNTEMLER}

Sol ana koroner arter hastalığı risk faktörlerinin akut koroner sendrom ve stabil koroner arter hastalığı üzerine etkisi kesitsel tipte ve tanımlayıcı bir araştırma olarak planland1. Bu çalışmaya Gaziosmanpaşa Tip Fakültesi Üniversite Hastanesinde Ocak 2004 ve Nisan 2012 tarihleri arasında akut koroner sendrom (AKS) ve kararlı angina pektoris (KAP) kliniği ile başvuran 15384 hastaya yapılan KAG sonucu izole sol ana koroner lezyonu hastalığı olan 320 hasta 13.09.2011 tarih ve 11-BADK-103 kayıt numaralı etik kurul onayı ile dahil edildi. Bu hastalardan 94 tanesinde LMCA hastalığı eş değeri olarak tanımladığımız \%70 ve üzerinde proksimal sol sirkümfleks (LCx) ve sol anterior desending arter (LAD) lezyonu olması, 40 hastada ise 
koroner arter by-pass cerrahisi (KABG) öyküsü olması nedeniyle çalışmaya alınmadı. Hastalardan 14 tanesi laboratuvar ve klinik verilerinin yetersiz olması nedeniyle çalışmadan çıkarıldı. İzole sol ana koroner lezyonu tanı$\mathrm{m}$ anjiyografik olarak vasküler lezyon ciddiyeti \%50 veya daha fazla tıkanıklık tespit edilen hastalarda tanımlandı. Toplam 172 izole sol ana koroner lezyonu hastası çalışmaya alındı. Çalışmaya alınan hastalar grup 1 ve grup 2 olarak gruplara ayrıldı. Grup 1'de 81 hasta grup 2'de 91 hasta yer almaktaydı. Anterior miyokard infarktüsü (Mİ), inferior Mİ, ST elevasyonsuz Mİ (NSTEMI), Kararsız angina (UAP) kliniği ile hastaneye başvuran ve KAG sonucu izole sol ana koroner lezyonu tanısı alan hastalar grup 1'e dâhil edildi. Stabil KAH kliniği ile hastaneye başvurup KAG sonucu izole sol ana koroner lezyonu tanısı alan hastalar grup 2'ye dâhil edildi. (Şekil 1: Çalışma akış şeması). Diğer yandan hasta grupları LMCA'da lezyonun yerine ve ciddiyetine göre alt gruplara ayrıld1. Grup 1 ve grup 2'deki toplam 172 hasta hastaneye geliş klinik tablolarının mortalite ve morbidite belirleyicileri olan diyabetes mellitus, hipertansiyon, hiperlipidemi, sigara, aile öyküsü, yaş, cinsiyet, sol ventrikül boyutları, sol ventrikül ejeksiyon fraksiyonu, beden kitle indeksi, boy, kilo, bel çevresi ve laboratuvar tetkikleri üzerine olan etkisi incelendi.

\section{İstatistiksel Analiz}

2004 Ocak ile 2012 Nisan arasında hastanemize AKS, SAP ile başvuran ve yapılan KAG sonucu izole sol ana koroner lezyonu tanısı alan hastaların geriye dönük hastane entegre bilgi sisteminden elde edilen verilerinin istatistiksel analizi için çalışmaya dahil edilen 172 hastada SPSS (Statistical Package for Social Sciences) for Windows 16.0 programı kullanıldı. SPSS programına alınan veriler değerlendirilirken tanımlayıcı istatistiksel metotların (Ortalama, Standart sapma) yanı sıra niceliksel verilerin karşılaştırılmasında normal dağılım gösteren parametreler Student T testi ile normal dağılım göstermeyen veriler ise Mann Whitney U testi ile değerlendirildi. Diğer yandan kategorik verilerin karşılaştırılmasında ise Ki-Kare testi kullanıldı. Sonuçlar \% 95’lik güven aralığında değerlendi- rildi. İstatistiksel olarak p değeri 0,05 altında olan sonuçlar anlamlı kabul edildi.

\section{BULGULAR}

Ocak 2004 ve Nisan 2012 tarihleri arasında yapılan KAG sonucu izole LMCA hastalığı tanısı alan hastaların \%53 (91 hasta) kararlı anjina pektoris, \% 47 (81 hasta) AKS hastalarından oluşmaktaydı. Hastaların yaş ortalaması erkeklerde $64 \pm 10$ kadınlarda $61 \pm 10$ idi. Toplam 172 çalışma hastasının 134 (\%78)'ü erkek, 38 (\%22)'i kadındı. İzole LMCA lezyonu saptanan hastaların 91'i SAP, 33'ü UAP, 23'ü NSTEMI, 14'ü inferior MI, 11'i anterior MI kliniği ile başvuran hastalardı. Çalışmamızda 100 hastada HT, 64 hastada dislipidemi, 51 hastada sigara öyküsü, 48 hastada diyabet, 36 hastada birinci derece yakın akrabalarında koroner arter hastalığı öyküsü mevcuttu. Grup 1'de 24 kadın ve 57 erkek hasta var iken grup 2'de 14 kadın ve 77 erkek hasta vardı. Cinsiyet açısından grup 1 ve grup 2 arasindaki fark istatistiksel olarak anlamlıd $1(\mathrm{p}=0.02)$. Grup l'de 81 hasta olup yaş ortalaması 63.5 \pm 10.0 , grup 2'de 91 hasta olup yaş ortalaması $62.6 \pm 9.7$ olup gruplar arasında yaş risk faktörü açısından istatistiksel olarak anlamlı fark saptanmadı ( $\mathrm{p}>0.05)$. Çalışmada 48 (\%28) hasta diyabetik olup bu hastaların 23'ü grup 1'de 25'i grup 2'de idi. Gruplar arasında diyabet açısından istatistiksel olarak anlamlı fark yoktu(p>0.05). Çalışmaya alınan hastaların 64 (\%37)'ünde dislipidemi mevcut olup bu hastaların 36'sı grup 1'de 28'i grup 2'de idi. İstatistiksel olarak grup 1 ve grup 2 arasından dislipidemi açısından istatistiksel olarak anlamlı fark saptanmadı ( $\mathrm{p}>0.05)$. Aile öyküsü mevcut olan hasta sayısı 36 olup bu hastaların 23'ü grup 1'de 13'ü grup 2'de idi. Gruplar arasında aile öyküsü olan hastalarda istatistiksel olarak anlamlı fark izlendi $(\mathrm{p}=0.02)$. Çalışmaya alınan hastaların 100 tanesinde (\%58) hipertansiyon olup bu hastaların 48'i grup 1'de 52'si grup 2'de bulunmaktaydı. Gruplar arasında hipertansiyon yönünden istatistiksel olarak anlamlı fark saptanmadı ( $>>0.05)$. Elli bir (\%29) hasta sigara kullanıyordu ve bu hastaların 23'ü grup 1'de 28'i grup 2'de bulunmaktaydı. Gruplar arasında sigara içiciliği açısından istatistiksek olarak anlamlı fark saptanmadı ( $\mathrm{p}>0.05)$. Grup 
1 ve grup 2 deki hastalar sol ventrikül (LV) çapları ve LV sistolik fonksiyonları açısından karşılaştırıldı. LV sistolik fonksiyonları ve çapları açısından gruplar arasında istatistiksel olarak yine anlamlı fark saptanmadı ( $\mathrm{p}>0.05)$. Diastolik fonksiyonlar ise yeterli veri elde edilemediğinden dolayı değerlendirilemedi. LV diastolik çapları açısından gruplar arasında istatistiksel olarak anlamlı fark saptan$\operatorname{mad}_{1}(\mathrm{p}>0.05)$. İzole sol ana koroner lezyonu hastalığında lezyon ciddiyeti açısından gruplar arasında istatistiksel olarak karşılaştırma yapıldı. Lezyon ciddiyeti açısından istatistiksel olarak gruplar arasında anlamlı fark saptanmadı ( $>0.05)$. (Tablo:3).

\begin{tabular}{|c|c|c|c|}
\hline Değişkenler & Grup $1(\mathrm{n}: 81)$ & Grup $2(n=91)$ & $\mathrm{P}$ değeri \\
\hline Yaş & $64 \pm 10$ & $63 \pm 10$ & 0.55 \\
\hline Cinsiyet (\%) & & & 0.02 \\
\hline Erkek & $57(80)$ & $77(76)$ & \\
\hline Kadın & $24(24)$ & $14(20)$ & \\
\hline $\begin{array}{l}\text { Diyabetes } \\
\text { Melllitus }\end{array}$ & $23(25)$ & $66(75)$ & 0.89 \\
\hline Hipertansiyon & $48(48)$ & $52(52)$ & 0.77 \\
\hline Aile Öyküsü & $23(63)$ & $13(37)$ & 0.02 \\
\hline Sigara & $23(45)$ & $28(55)$ & 0.73 \\
\hline Dislipidemi & $36(56)$ & $28(54)$ & 0.06 \\
\hline LVEF & $53.2 \pm 9.2$ & $52.4 \pm 11.7$ & 0.67 \\
\hline
\end{tabular}

Tablo 2: AKS (Grup 1) ve SAP (Grup 2) laboratuvar değerlerinin karşılaştırılması

\begin{tabular}{|c|c|c|c|}
\hline Değişkenler & Grup1 (n:81) & Grup $2(n=91)$ & p değeri \\
\hline Glukoz & $139.5 \pm 83.2$ & $133.0 \pm 72.2$ & 0.62 \\
\hline BUN & $19.5 \pm 8.6$ & $17.4 \pm 9.1$ & 0.07 \\
\hline Kreatinin & $1.08 \pm 0.9$ & $0.94 \pm 0.24$ & 0.16 \\
\hline Ürik asit & $5.4 \pm 1.4$ & $5.1 \pm 1.3$ & 0.31 \\
\hline CRP & $8.02 \pm 5.9$ & $8.3 \pm 6.42$ & 0.85 \\
\hline Total Kolesterol & $186.2 \pm 71.6$ & $205.0 \pm 50.3$ & 0.07 \\
\hline Trigliserit & $167.8 \pm 119.6$ & $67.4 \pm 64.9$ & 0.98 \\
\hline LDL & $118.0 \pm 58.7$ & $137.3 \pm 47.0$ & 0.03 \\
\hline HDL & $37.8 \pm 10.3$ & $38.3 \pm 9.9$ & 0.76 \\
\hline Beyaz Küre (103) & $10523 \pm 2545$ & $10225 \pm 2185$ & 0.89 \\
\hline Nötrofil & $5.79 \pm 3.02$ & $4.68 \pm 1.37$ & $<0.01$ \\
\hline Lenfosit & $1.92 \pm 0.79$ & $2.19 \pm 0.85$ & 0.04 \\
\hline Monosit & $0.59 \pm 0.29$ & $0.49 \pm 0.21$ & 0.01 \\
\hline $\mathrm{Hgb}$ & $13.04 \pm 1.89$ & $13.8 \pm 1.79$ & $<0.01$ \\
\hline PLT (103) & $346520 \pm 105$ & $292450 \pm 859$ & 0.53 \\
\hline RDW & $14.7 \pm 1.85$ & $14.2 \pm 1.54$ & 0.03 \\
\hline MPV & $8.7 \pm 1.38$ & $8.3 \pm 1.13$ & 0.06 \\
\hline Nötrofil / Lenfosit & $3.5 \pm 4.3$ & $2.1 \pm 1.43$ & $<0.01$ \\
\hline \multicolumn{4}{|c|}{$\begin{array}{l}\text { n: Hasta sayısı. Koyu renk ile belirtilen değerler istatiksel olarak } \\
\text { anlamlıdır. BUN: Kan üre azotu; CRP: C reaktif protein; LDL: } \\
\text { Düşük dansiteli lipoprotein; HDL: Yüksek dansiteli lipoprotein; } \\
\text { HGB: Hemoglobin; PLT: Platelet sayısı; RDW: Eritrosit dağlım } \\
\text { aralığ1; MPV: Ortalama platelet volümü AKS: Akut koroner sen- } \\
\text { drom, SAP: Stabil koroner arter hastalığı. }\end{array}$} \\
\hline
\end{tabular}

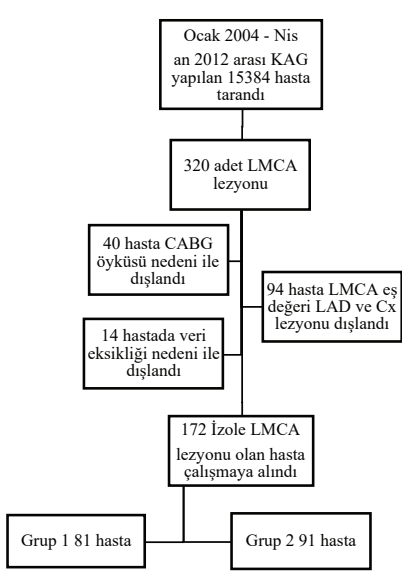

Şekil 1: Çalışma Akış Şeması

KAG : Koroner angiografi, LMCA :Sol Ana Koroner Arter, CABG: Koroner arter by-pass cerrahisi, LAD: Sol Ön İnen Arter, CX: Sirkümfleks arter. 
Çalışmaya aldığımız grup 1 ve grup 2 deki toplam 172 hasta laboratuvar tetkikleri açısından karşılaştırıldı. Grup

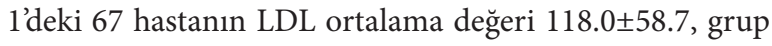
2'de 76 hastanın LDL ortalama değeri 137.3 $\pm 47,0$ olarak hesaplandı ve gruplar arasında istatistiksel olarak anlamlı fark saptand1 $(\mathrm{p}=0.03)$. Grup 1'deki 64 hastanın nötrofil ortalama değeri 5.79 \pm 3.02 , grup 2'deki 75 hastanın nötrofil ortalama değeri $4.68 \pm 1.37$ olup gruplar arasında anlamlı fark saptandı ( $\mathrm{p}=0.005)$. Grup 1'deki 73 hastanın lenfosit ortalama değeri 1.92 \pm 0.79 , grup 2'deki 83 hastanın lenfosit ortalama değeri $2.19 \pm 0.85$ olarak ölçüldü ve gruplar arasında anlamlı fark saptand1 $(\mathrm{p}=0.04)$. Grup 1'deki 73 hastanın monosit ortalama değeri $0.59 \pm 0.29$, grup 2'deki 81 hastanın monosit ortalama değeri $0.49 \pm 0.21$ olarak ölçüldü ve gruplar arasında anlamlı fark saptandı $(\mathrm{p}=0.01)$. Grup 1'deki 73 hastanın hemoglobin ortalama değeri 13.04ะ1.89, grup 2'deki 86 hastanın hemoglobin ortala-

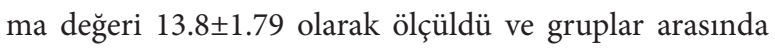
anlamlı fark saptandı $(\mathrm{p}=0.005)$. Grup 1'deki 73 hastanın RDW ortalama değeri $14.7 \pm 1.85$, grup 2'deki 84 hastanın

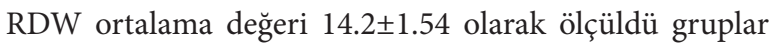
arasında RDW açısından anlamlı fark saptandı $(\mathrm{p}=0.03)$. Nötrofil/lenfosit oranı açısından grup 1'de 73 hasta grup 2'de bulunan 83 hasta karşılaştırıldı. Grup 1'de ortalama nötrofil/lenfosit oran1 3.5 \pm 4.3 grup 2'de ise $2.1 \pm 1.43$ olup gruplar arasında istatistiksel olarak anlamlı fark saptan$\mathrm{d}_{1}(\mathrm{p}=0.01)$. Grup 1'de 73 hastanın grup 2'de 83 hastanın nötrofil/lenfosit oranı grup 1'de ortalama değeri $3.5 \pm 4.3$, grup 2'de ortalama değeri $2.1 \pm 1.43$ olup istatistiksel olarak gruplar arasında anlamlı fark saptand $1(\mathrm{p}=0.01)$.

\section{TARTIŞMA}

Yapılan çalışmaların meta-analizlerinden elde edilen verilere göre KAH'in tüm dünyada epidemik bir sağlık sorunu olduğu, neden olarak ise ateroskleroz ve üzerine binen akut trombotik hadiseler vurgulanmaktadır. ${ }^{9}$ Aterosklerotik kardiyovasküler hastalık terimi $\mathrm{KAH}$, inme ve periferik vasküler hastalıkları kapsamakta olup hepsinin altında yatan ana patoloji aterosklerozdur. ${ }^{10,11}$
Yapılan prospektif çalışmalarda diyabetin KAH için her iki cinsiyette de bağımsız bir risk faktörü olduğu gösterilmiştir. ${ }^{12,13}$ Mortalite ve morbidite açısından diyabeti olmayan hastalarla karşılaştırıldığında diyabetik olup MI geçiren hastalarda riskin daha yüksek olduğu saptanmıştır. ${ }^{14,15}$ Çalışmada diyabetik hasta sayısı 99 olup toplam hasta sayımızın \% 54'nü oluşturmaktaydı. Hastaların yarısından fazlası diyabet olup tüm hastalar koroner arter hastasıydı. Çalışmada diyabetik hastalarda AKS ve kronik kararlı KAH arasında diyabetik açıdan anlamlı fark saptanmadı. Çalışmada bulunan 100 (\%58) hipertansif hastanın gruplar arasında klinik geliş tablosu üzerine hipertansiyonun etkisi açısından istatistiksel olarak anlamlı fark saptanmadı. Yine çalışmada 54 (\%31) hastada dislipidemi mevcut olup, dislipidemili olan hastalarda gruplar arasında başvuru kliniği açısından anlamlı fark izlenmedi. Çalışmada grup 1 ve grup 2 de aile öyküsü açısından grup 1 lehine istatistiksel olarak anlamlı fark saptandı ( $\mathrm{p}=0.02)$. Aile öyküsü açısından çalışmanın sonuçları daha önceki çalışmalardan elde edilen verileri desteklemektedir. Koroner arter hastalığ 1 erkeklerde olduğu gibi kadınlarda da mortalite ve morbiditenin en önemli nedenlerinden biridir. Bu gün dünyada toplam kadın ölümlerinin neredeyse üçte birinin koroner arter hastalığına bağlı olduğu bilinmektedir. ${ }^{16}$ Epidemiyolojik çalışmalar, erkeklere göre kadınlarda koroner arter hastalığı başlangıcının yaklaşık on yıl kadar sonra ortaya çıktığını ve prevelansının ise menopoz sonrası hızla arttığını göstermektedir. Bunun sebebinin ise premenopozal dönemde östrojenin kardiyoprotektif etkisine bağlı olduğu düşünülmektedir. ${ }^{16}$ Çalışmadaki toplam 172 hastanın 134 (\%78)'ü erkek, 38 (\%22)'i kadın olup cinsiyet açısından grup 1 ve grup 2 arasındaki fark istatistiksel olarak anlamlı olarak saptand $1(\mathrm{p}=0.02)$.

Grup 1 ve grup 2'de yaş risk faktörü açısından istatistiksel olarak anlamlı fark saptanmadı $(\mathrm{p}=0.55)$. Çalışmadan elde edilen bu veriler AKS'de erkek cinsiyetin bağımsız bir risk faktörü olduğunu desteklemektedir. 
İçilen sigara miktarı ile orantılı olarak aterosklerotik vasküler hastalık riski 2-3 kat artmakla birlikte, MI ve KVS hastalıklarına bağlı ölüm erkeklerde 2,7 kat kadınlarda 4,7 kat artmakta olduğu gösterilmiştir. ${ }^{17,18}$ Sigara KAH hastalarında fibrinojen seviyelerini artırmakla birlikte trombosit agregasyonunu artırarak akut trombotik olaylara zemin hazırlar. ${ }^{19}$ Çalışmada 51 hasta (\%29) sigara kullanmaktaydı. Çalışmada gruplar arasında sigara içiciliği açısından istatistik olarak anlamlı fark saptanmadı. Yapılan çalışmalarda plak rüptürü oranı inflamatuar belirteçleri yüksek olan hastalarda daha yüksek bulunmuştur. Miyokart hücre hasarı sonucu azda olsa sistemik inflamasyon oluşmakla birlikte, sistemik ve lokal inflamasyonun, AKS patogenezinde hem presipitan faktör olarak hem de predispozan faktör olarak rol oynadığ ${ }_{1}$ gösterilmiştir. ${ }^{1}$ Çalışmada nötrofil, lenfosit, monosit ve nötrofil/lenfosit oranı AKS grubu lehine istatistiksel olarak anlamlı olarak saptandı. Çalışmadan elde edilen bu veriler yukarıda anlatılan AKS patogenezindeki inflamatuar süreci desteklemektedir. Lipsic ve ark.'nın 1769 hastada yaptıkları çalışma sonucu aneminin MI geçiren hastalarda ilk 30 günlük mortalitede belirgin artışa sebep olduğunu tespit etmişlerdir. ${ }^{20}$ Yukarıda literatürlerde bahsedildiği gibi AKS’li anemik hastalarda bizim çalışmamızda da hgb değerleri açısından gruplar karşılaştırıldığıında kronik SAP hastalarına karşı AKS'li hastalar lehine istatistiksel olarak anlamlı fark saptandı.

AKS nedeni ile koroner yoğun bakım ünitesine alınan yüksek RDW değeri olan hastaların altı aylık takiplerinde yüksek RDW değerininin AKS'li hastalarda mortalite ile ilişkili olduğu görülmüştür. ${ }^{21} \mathrm{Bu}$ çalışmada da gruplar arasında RDW açısından AKS grubu lehine istatistiksel olarak anlamlı fark saptandı. Çalışmadan elde edilen bu veri daha önce yapılan çalışmaları desteklemekte olup yüksek RDW değerinin koroner olayları öngörmede önemli olabileceğini düşündürmektedir.

\section{SONUÇ}

$\mathrm{Bu}$ çalışmada izole sol ana koroner arter hastalığı tespit edilen ve AKS ile başvuran 81 hasta ve kronik kararlı an- jina kliniği ile başvuran 91 hastanın klinik ve laboratuvar özellikleri karşılaştırıldı. Gruplar arasında cinsiyet, yaş ve aile öyküsü açısından AKS grubu lehine istatistik olarak anlamlı sonuçlar elde edildi. Mortalite belirleyicisi olduğu düşünülen laboratuvar parametrelerinden ise nötrofil, lenfosit, nötrofil/lenfosit oranı, RDW, hemoglobin değerinin yine gruplar arasında AKS grubu lehine anlamlı olarak yüksek olduğu görüldü. Hastane entegre bilgi sisteminden geriye dönük çalışmaya alınan hastaların çoğunun beden kitle indeksi, boy, kilo, bel çevresi ölçümleri eksik olduğu için çalışmada bu veriler değerlendirilmedi. Çalışma retrospektif ve sınırlı sayıda hastayı içermesi nedeniyle bu konuda prospektif ve daha fazla sayıda hasta katılımının olduğu çalışmalara ihtiyaç duyulmaktadır.

\section{Etik Kurul Onayı}

13.09.2011 tarihinde 11-BADK-103 kayıt numarası ile Gaziosmanpaşa Üniversitesi Tip Fakültesi Dekanlığından alınmıștır 
Sakarya Tip Dergisi 2021;11(2):272-278

ÖZTÜRK, İzole Sol Ana Koroner Arter Hastalı̆̆ında Risk Faktörlerinin Etkisi

\section{Kaynaklar}

1. Cusack MR, Marber MS, Lambiase PD, Bucknall CA, Redwood SR. Systemic inflammation in unstable angina is the result of myocardial necrosis. J Am Coll Cardiol. 2002;39(12):191723.

2. Onat A, Soydan I, Tokgozoglu L, Sansoy V, Koylan N, Domanic N, et al. Guideline implementation in a multicenter study with an estimated $44 \%$ relative cardiovascular event risk reduction. Clin Cardiol. 2003;26(5):243-9.

3. Kuo CC, Chen HH, Wang SP, Grayston JT. Identification of a new group of Chlamydia psittaci strains called TWAR. J Clin Microbiol. 1986;24(6):1034-7.

4. Cohen MV, Cohn PF, Herman MV, Gorlin R. Diagnosis and prognosis of main left coronary artery obstruction. Circulation. 1972;45(1 Suppl):I57-65.

5. Lavine P, Kimbiris D, Segal BL, Linhart JW. Left main coronary artery disease. Clinical, arteriographic and hemodynamic appraisal. Am J Cardiol. 1972;30(8):791-6.

6. Ryan TJ, Antman EM, Brooks NH, Califf RM, Hillis LD, Hiratzka LF, et al. 1999 update: ACC/AHA Guidelines for the Management of Patients With Acute Myocardial Infarction: Executive Summary and Recommendations: A report of the American College of Cardiology/American Heart Association Task Force on Practice Guidelines (Committee on Management of Acute Myocardial Infarction). Circulation. 1999;100(9):1016-30.

7. Yilmaz H, Sancar O, Demir İ, Başarııı I', at al. "Sol ana koroner artere stent uygulamart: Erken -geç dönem sonuçları" Anadolu Kardiyoloji Dergisi 1, no. 4 (2001): 255-258.

8. Karaman K, Aygüç B, Arısoy A, Karayakalı M, Yllmaz S, Karaman S, et all. Kararl Anjina Pektorisli Hastalarda Koroner Arter Lezyon Șiddetinin Eritrosit Dağllım Genişliği ve Ayak Bileği-Kol Basınç İndeksi ile İlişsisi. Sakarya Tip Dergisi. 2018; 8(2): 3019-311

9. Fuster V, Corti R, Badimon JJ. The Mikamo Lecture 2002. Therapeutic targets for the treatment of atherothrombosis in the new millennium--clinical frontiers in atherosclerosis research. Circ J. 2002;66(9):783-90.

10. Ford ES. Leukocyte count, erythrocyte sedimentation rate, and diabetes incidence in a national sample of US adults. Am J Epidemiol. 2002;155(1):57-64.

11. Crook MA, Tutt P, Pickup JC. Elevated serum sialic acid concentration in NIDDM and its relationship to blood pressure and retinopathy. Diabetes Care. 1993;16(1):57-60.
12. National Cholesterol Education Program Expert Panel on Detection E, Treatment of High Blood Cholesterol in A. Third Report of the National Cholesterol Education Program (NCEP) Expert Panel on Detection, Evaluation, and Treatment of High Blood Cholesterol in Adults (Adult Treatment Panel III) final report. Circulation. 2002;106(25):3143-421.

13. Grundy SM, Benjamin IJ, Burke GL, Chait A, Eckel RH, Howard BV, et al. Diabetes and cardiovascular disease: a statement for healthcare professionals from the American Heart Association. Circulation. 1999;100(10):1134-46.

14. Stone PH, Muller JE, Hartwell T, York BJ, Rutherford JD, Parker CB, et al. The effect of diabetes mellitus on prognosis and serial left ventricular function after acute myocardial infarction: contribution of both coronary disease and diastolic left ventricular dysfunction to the adverse prognosis. The MILIS Study Group. J Am Coll Cardiol. 1989;14(1):49-57.

15. Smith JW, Marcus FI, Serokman R. Prognosis of patients with diabetes mellitus after acute myocardial infarction. Am J Cardiol. 1984;54(7):718-21.

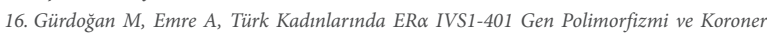
Arter Hastalı̆̆ Arasındaki İlişki. MN Kardiyoloji 2018 ;25(1) : 13-17.

17. Castelli WP, Garrison RJ, Dawber TR, McNamara PM, Feinleib M, Kannel WB. The filter cigarette and coronary heart disease: the Framingham study. Lancet. 1981;2(8238):109-13.

18. Wilhelmsson C, Vedin JA, Elmfeldt D, Tibblin G, Wilhelmsen L. Smoking and myocardial infarction. Lancet. 1975;1(7904):415-20.

19. Rival J, Riddle JM, Stein PD. Effects of chronic smoking on platelet function. Thromb Res. 1987;45(1):75-85.

20. Lipsic E, van der Horst IC, Voors AA, van der Meer P, Nijsten MW, van Gilst WH, et al. Hemoglobin levels and 30-day mortality in patients after myocardial infarction. Int $J$ Cardiol. 2005;100(2):289-92.

21. Nabais S, Losa N, Gaspar A, Rocha S, Costa J, Azevedo P, et al. Association between red blood cell distribution width and outcomes at six months in patients with acute coronary syndromes. Rev Port Cardiol. 2009;28(9):905-24. 